\title{
REPRESENTACIONES DEL MUNDO RURAL EN LA OBRA PABLO O LA VIDA EN LAS PAMPAS DE EDUARDA MANSILLA. VISIONES DE UNA INTÉRPRETE CULTURAL
}

\author{
Representations of the rural world in Pablo o la vida en las pampas \\ by Eduarda Mansilla. Visions of a cultural interpreter
}

\author{
Milagros Rojo Güiñazú* \\ Universidad Nacional del Nordeste \\ milagrosguinazu@gmail.com
}

Palabras clave

representaciones;

rural;

barbarie;

gaucho;

intérprete

Keywords

representations;

rural;

barbarism;

gaucho;

interpreter

\section{Resumen}

Durante el siglo XIX fueron muchas las escritoras que encontraron sus espacios de circulación y ciertos reconocimientos; no obstante, no todas ellas han tenido un plano de igualdad en la historia de la literatura argentina, principalmente cuando se definió el mapa literario en el siglo XX.

En este ensayo queremos comentar el caso de Eduarda Mansilla, puntualmente el de su obra Pablo o la vida en las pampas, obra que configura una representación del mundo rural en un período de la historia argentina en donde la figura del gaucho comienza a pensarse en el centro de los tópicos de varios escritores.

En su novela Mansilla nos conduce a revisar, no solamente los tópicos propuestos por Sarmiento en Facundo, sino a repensar los pares dicotómicos que han definido la primera parte del siglo, la topografía de la barbarie y a conocer el mundo íntimo de un grupo social vulnerado.

Desde su lugar de intérprete cultural muestra la Argentina del siglo XIX, en francés, con una exquisitez sinigual, y luego en español, con traducciones e intervenciones en su obra.

\begin{abstract}
During the 19th century, many writers found their spaces for circulation and certain recognition; however, not all of them have had a level of equality in the history of argentine literature, mainly when the literary map was defined in the 20th century.

In this essay we want to comment on the case of Eduarda Mansilla, specifically that of her work Pablo o la vida en las pampas; work that configures a representation of the rural world in a period of argentine history where the figures of the gaucho begin to be thought at the center of the topics of several writers.

In her novel Mansilla leads us to review, not only the topics proposed by Sarmiento in Facundo; but rather to rethink the dichotomous pairs that have defined the first part of the century, the topography of barbarism and to know the intimate world of a violated social group.

From her place of cultural interpreter, she shows Argentina in the 19th century, in French, with a unique delicacy, and then in Spanish, with translations and interventions in her work.
\end{abstract}




\title{
Representaciones del mundo rural en la obra Pablo o la vida en las pampas de Eduarda Mansilla. Visiones de una intérprete cultural
}

\begin{abstract}
$Y$ de ahi cómo, en un pais donde no deberían existir diferentes clases, distinciones sociales de ninguna especie, donde el sentimiento democrático, habiendo echado raices desde el primer día, habia abolido toda sombra de privilegio, debia surgir el terrible enemigo que, desde su nacimiento, iba a dividir y por mucho tiempo a la República en dos bandos: el hombre de la ciudad y el de las campañas, el civilizado y el gaucho.
\end{abstract}

Eduarda Mansilla

Eduarda Mansilla fue una escritora argentina del siglo XIX, en un tiempo en el que el lugar de la mujer, como escritora y como intelectual, era problemático. No solamente referimos a los lugares designados al género, sino puntualmente a las limitaciones y fronteras que muchas de ellas se atrevieron a cruzar. Al igual que otras escritoras, publicó algunas de sus obras, en unos momentos, escondida detrás de seudónimos; $y$, en otros, se permitió exhibir completamente su autoría. No fue una mujer cualquiera, no solo por su genealogía familiar, ${ }^{1}$ sino porque fue reconocida como escritora primero en Europa.

Así lo presenta María Rosa Lojo:

Eduarda, recuerda Francine Masiello (óp. cit., 43) inaugura así una larga cadena de escritoras de la clase alta argentina que elegirán al francés como lengua literaria. Pero en este caso no se trata aún del problema de expresar el mundo íntimo, amoroso, que de algún modo el francés ocultaría y legitimaría, púdicamente, en el acto mismo de revelarlo, como ocurre con el género de los "versos franceses", cultivados más tarde por Delfina Bunge y Victoria Ocampo (Sarlo, 1998, 122 y ss.). Lo que domina es la búsqueda del interlocutor validante: un público europeo capaz de "consagrar", (y consagrarla, por tanto, frente a sus compatriotas). (1999, p. 2-3)

Retomando la noción de Drucaroff (2010), hay en Eduarda Mansilla la asunción, a través de su escritura, de un compromiso con su mundo, con su tiempo y con las problemáticas vigentes en ese momento.

Así, desempeña el rol de mediadora entre sociedades y culturas:

Escritora viajera que vincula mundos y lenguas, mantiene siempre la inteligencia de la doble crítica. (...) la mirada va de un lado al otro, sopesa y valora, para desembocar en un proceso

1. Eduarda Damasia Mansilla nace en Buenos Aires en 1834, y fallece en la misma ciudad en 1892. Perteneció a una familia prestigiosa del Buenos Aires del XIX. Hija de un héroe de la Independencia y de la Batalla de la Vuelta de Obligado (general Lucio Norberto Mansilla) y de Agustina Ortiz de Rozas, sobrina del Restaurador don Juan Manuel de Rosas, hermana del militar, escritor y dandy, Lucio V. Mansilla. 
innovador que conduce a la afirmación de la voz autorial, capaz de crear un espacio único desde donde hablar por cuenta propia. (Lojo, 2007, p. 18-19)

En 1868, Eduarda Mansilla escribe en francés la novela Pablo ou la vie dans les pampas y un año después la publica en Francia, en la Revista L'Artisté de París, y posteriormente en la librería Hachette. Con esta obra se propuso explicar a los franceses la Argentina de su tiempo, el mundo rural y la tan temida barbarie hispanoamericana. Escoge el idioma de sus receptores, lo que la transforma también en una intérprete (traductora) cultural que desglosa la identidad hispanoamericana y rioplatense con una destreza singular.

Así lo enuncia en una carta personal que le escribe Víctor Hugo:

Su libro me ha cautivado. Yo le debo horas cautivantes y buenas. Usted me ha mostrado un mundo desconocido. Usted escribe una excelente lengua francesa, y resulta de profundo interés ver su pensamiento americano traducirse en nuestro lenguaje europeo. Hay en su novela un drama y un paisaje: el paisaje es grandioso, el drama es conmovedor. Se lo agradezco señora, y rindo a sus pies mis homenajes. (Carta de Víctor Hugo a Eduarda Mansilla, en Chikiar Bauer, 2013, p. 45)

La obra de Mansilla representó un acontecimiento importante para el ámbito literario de ese momento, considerándosela precursora en muchos aspectos y representativa en tanto escrita por una mujer, con las complejidades que ello involucraba.

La versión en español de esta novela fue editada y traducida por su hermano Lucio Victorio, quien realizó esta tarea para el diario La Tribuna. Así, la obra aparece en formato de folletín, en menos de treinta números (del 6033 al 6059), distribuidos en veinte entregas.

En el año 2007, la Biblioteca Nacional, en el marco de una colección denominada Los raros, publica una nueva edición de esta novela. Esta versión se basa en la traducción de Lucio V. Mansilla, pero añade la edición crítica y anotada de María Gabriela Mizraje. El aporte de esta actualizada edición de la obra permite poner en diálogo a una crítica contemporánea con el traductor de Eduarda.

Mizraje (2007) recupera un componente fundamental para la obra y para la consideración de la escritora como intérprete cultural: el apéndice con notas de la obra original.

Con un claro destinatario de su obra, el autor de Los Tres Mosqueteros, Alejandro Dumas, la escritora demuestra que puede no ser una salvaje, desdibujando el estigma de la barbarie que los unitarios proscriptos habían adjudicado a su tío materno y al partido federal. Es esta misma inquietud la que atraviesa las páginas de esta novela, escrita en francés, aunque no exclusivamente para franceses,

2. Durante su residencia en Francia -mientras acompañaba a su esposo que cumplía con sus misiones en el extranjero-, la novela aparece por entregas en la revista de Arsene Houssaynne, el escritor que podría considerarse -dentro del círculo literario de la Francia de esa época- el más atento con las mujeres. Posteriormente, en 1869, la obra es editada como libro por E. Lachaud. 
pero sí al menos para el mundo civilizado que conoce de manera fragmentada o distorsionada ese país del sur al que Eduarda y su marido representan.

Es posible también pensar al uso del francés como una manera sutil de amparo u ocultación del yo, a la vez que le da cierto poder simbólico que le permite introducirse, siendo mujer, en el debate político, opinar como lo hacían los varones autorizados, y no pocas veces, en contra de ellos.

Igual que Sarmiento en el Facundo, Eduarda pretendía "explicarles" la Argentina a los europeos y, sobre todo, a los franceses (aunque, a diferencia de Sarmiento, lo hizo en la propia lengua de sus "lectores modelo").

Francia fue siempre para Eduarda un país ejemplar, sinónimo del buen vivir, del buen comer, del vestir elegante, del gusto en todo. Ella misma se reconoce una lectora asidua de la literatura francesa, clásica y romántica, y pudo transformarse en una autora bilingüe con mucha facilidad. Sin embargo, su actitud ante esa cultura (que sin duda admiraba, y de la que participaba también) no pretendía imitar o disculpar la "barbarie" argentina ante la civilización europea.

Entre los hechos que se suceden en la publicación de la novela de Eduarda hay una cuestión digna de ser destacada. En primer lugar, la autora traduce la obra para los extranjeros y la ofrece en tres entregas en forma de folletín en el diario L'Artiste. En esta presentación la escritora escoge el francés como lengua y la trabaja al nivel de un diccionario bilingüe con sus notas al pie. La obra, firmada por E. M. García, se publica como La vida en las pampas. Luego, Lucio la retraduce y se enfrenta con la glosa (Mizraje, 2007, p. 55). Las cuarenta y cinco notas del original francés se esfuman. $\mathrm{Su}$ traductor subsume en la glosa, sin aclaración alguna, las orientaciones que Eduarda pensó para sus lectores parisinos con el fin de referir a cuestiones locales (fauna, flora, hábitos, oficios, voces argentinas).

Eduarda llega primero que su hermano a la novela, pero Lucio la folletiniza. En la traducción no solamente hace el pasaje de una lengua a otra, sino que altera la disposición textual de la obra. Las notas que Eduarda redactó, como una verdadera intérprete cultural, son eliminadas por su traductor. Cuestión que se soluciona con su recuperación en la edición de Mizraje.

En este minucioso apéndice con notas encontramos referencias a expresiones que, por capítulo, la escritora consideró dignas de ser distinguidas y explicadas. El valor de su rol como intérprete radica justamente en eso. Cada expresión o término se acompañaba por la correspondiente conceptualización y por la enunciación del término en francés. La autora va al detalle de una traductora e intérprete cultural, con sensibilidad artística. Prioriza la interpretación del lector respecto de un mundo desconocido. Esta marca identitaria de la escritora se diluye detrás de la interpretación del traductor.

Veamos algunos ejemplos:

Papeleta (sic, por 'papeleta'): certificado de exoneración del servicio militar. (certificat d'exonération du service militaire).

yerba: especie de té indígena. (espéce de thé indigénen).

pago: sitio. (endroit). (Mizraje, 2007, p. 81-84). 
Por esto, observamos que el rol de la escritora como intérprete cultural sufre un borramiento tras la traducción de su hermano. Pero no es absoluto, aunque sí se pierde el apéndice con notas que Eduarda redacta. Vale aquí reiterar que la obra de Mizraje recupera la voz de Eduarda Mansilla como escritora e intérprete cultural.

Ahora bien, regresando a la novela, destacamos que Mansilla se esmera para que los europeos comprendan la Argentina rural de su tiempo, ese territorio bárbaro que tan dignamente defiende con una pluma exquisita. De esta forma, en esta obra posicionada en la pampa a mediados del siglo XIX, la escritora nos conduce a un recorrido en el que podemos conocer la vida rural, a partir de las descripciones de la geografía, la presentación y explicación de usos y costumbres de ese ámbito, y de los valores y creencias que consolidan a sus habitantes. Logra trazar un paisaje histórico que opone a las costumbres y valores de la vida urbana con el objetivo de realizar una suerte de denuncia por el maltrato y la exclusión del gaucho por parte del Estado.

Podríamos considerar que la novela de Mansilla se configura desde su representación del paisaje, en el que centraliza su mirada. Tal vez, en retrospectiva con otras obras que pretendieron mostrar el paisaje de la pampa, Pablo es generosa y deliciosa, y completa -si se quiere- la representación del mundo rural con una visión desarticuladora respecto de ciertas dicotomías que con anterioridad sesgaron su configuración.

Graciela Batticuore propone la noción de escritora como intérprete cultural y dice:

La comunicación humana es una traducción (...). Entender al otro y hacerse entender (también dentro de una misma lengua) implica siempre un complejo proceso que requiere esfuerzos y pasajes a veces difíciles de sortear, para atravesar las fronteras del yo buscando conciliar los propios códigos con los del interlocutor. Las diferencias sociales, generacionales, sexuales, temporales afectan constantemente ese proceso y es así como los hablantes, como los intérpretes, enfrentan a cada momento la amenaza del malentendido. Su trabajo consiste precisamente en desafiar el caos de la incomprensión. (2005, p. 246)

Tal como enunciamos con anterioridad, Mansilla escribe para mostrar a los europeos la Argentina, y se presenta como intérprete cultural de la realidad argentina, de su contexto, de sus personajes, de sus problemáticas. Concentrando su mirada en la geografía argentina, la figura del gaucho, y la dicotomía civilización y barbarie.

Ella nos entrega la figura y la voz del gaucho de las pampas desde una nueva perspectiva. Su gaucho (Pablo) será, dentro del sinfín de personajes y tipos humanos que se representan en la historia, una víctima de la lucha de poderes entre los mismos de siempre: unitarios/federales. Tal vez por ser una obra escrita y publicada primeramente en el extranjero, o por el influjo de otras culturas, Mansilla nos brinda una versión diferente.

Tal como propone Batticuore, Eduarda altera los roles asignados a civilizados y bárbaros, fundando una disyuntiva muy interesante respecto de lo planteado acerca de la cultura nacional. 
Las novelas de Eduarda Mansilla plantean una suerte de dilema inherente a la cultura nacional: si bien no saber leer puede ser la causa de los conflictos que asedian a los personajes, saber hacerlo tampoco garantiza el orden de la vida civilizada. Por el contrario, a veces los letrados son los seres más temibles y perversos. Si bien este planteo funciona también para gran parte de la literatura antirrosista cuando ella se ocupa de singularizar la figura maquiavélica de un rosas letrado y poderoso, por su parte Mansilla revierte los destinatarios de la acusación apuntando al partido unitario y sus líderes. En sus novelas son ellos los responsables de todas las desgracias contra el pueblo y los culpables de poner su saber al servicio de los intereses facciosos que perjudican a los inocentes. (Batticuore, 2005, p. 253)

Eduarda concibe la figura del gaucho como un ser primario e inculto; no obstante, también lo piensa como alguien dócil y honrado que sufre la condena de verse arrastrado por las injusticias que llevan su nombre. El gaucho malo, como puede concebirse en Sarmiento e incluso en Hernández, no se construye a través de la escritura de Eduarda; pese a ello, sí presenta a un gaucho hostigado por sujetos que solo responden a las órdenes de ciertas fuerzas políticas y de la ciudad, profundizando la grieta dicotómica ciudad/campo.

Así lo leemos en la novela:

y de ahí cómo, en un país donde no deberían existir diferentes clases, distinciones sociales de ninguna especie, donde el sentimiento democrático, habiendo echado raíces desde el primer día, había abolido toda sombra de privilegio, debía surgir el terrible enemigo que, desde su nacimiento, iba a dividir y por mucho tiempo a la república en dos bandos: el hombre de la ciudad y el de las campañas, el civilizado y el gaucho. (Mansilla, 2007, p. 218)

Para la autora ni la ciudad ni el partido unitario encarnan a la civilización. Será un desierto mucho peor que la pampa (Lojo, 1999) para los personajes de la novela, y sus integrantes se caracterizarán por ser duros, inhumanos e indiferentes al sufrimiento. La escritora simplemente muestra un país sacudido por una cruel disputa política que se vulnera y agrede de manera similar. El gaucho y su gente se exponen como un grupo social ajeno a esa lucha, pero que deben pagar con creces las consecuencias recibiendo, usando las palabras de Mansilla: "Por todas partes abusos" (2007, p. 247).

Pablo, tal como lo enuncia Eduarda en el capítulo VI de la novela, es una víctima real y concreta de ambos sistemas de gobierno: "Unitarios y federales, todos son iguales. Yo los aborrezco a todos, como ellos nos aborrecen a nosotros, pobres gauchos” (Mansilla, 2007, p. 165).

Así, se retoma el tópico vinculado con el gaucho y la autoridad. Según Mansilla, la autoridad no representa ni la justicia ni la civilización, sino un brutal atropello a su legitimidad como sujeto.

María Rosa Lojo lo escribe con estas palabras: 
Pablo descree finalmente tanto de federales como de unitarios: unos y otros - dice- utilizan al gaucho para su provecho y, bajo la proclama de patria y libertad lo despojan de ambas (...). E1 joven se convertirá en desertor, y será injustamente fusilado junto con su amigo el "gaucho malo". (1999, p. 5)

Eduarda se adelanta a los escritores de su tiempo. Toma un personaje y un paisaje y los presenta en esta novela. Pero su mirada es transgresora. La base de su transgresión está en que desarrolla la noción de que ambos sistemas (unitarios y federales) son iguales en lo que refiere al tratamiento del gaucho.

Recordemos que en este momento el par dicotómico civilización-barbarie ubica a los escritores de uno u otro bando. Mientras que Eduarda se posiciona en un lugar en donde ya nada es absoluto.

"Nuestros legisladores tienen horror a la conscripción; pero cuando el gobierno quiere, cuando es necesario, el pobre gaucho está sujeto a la leva de esa autoridad que le hace prisionero en nombre de esa ley" (Mansilla, 2007, p. 107). De este modo, Mansilla ficcionaliza la cuestión del gaucho maltratado y excluido de la justicia, adelantándose a su hermano y a José Hernández, logrando, además, una perspectiva que ninguno de ellos desarrolla: la profunda visión de la interioridad del gaucho, el desamparo de las mujeres, marginadas entre los marginales, "locas" que se oponen a la ley de la violencia (que es la ley de los "héroes") para salvar a sus hijos. Desarticula los valores y disvalores asociados de manera rígida a las antinomias civilización/barbarie, unitarios/federales, ciudad/campaña; y revisa los tipos y tópicos pampeanos.

Esta novela (la novela de las guerras civiles y del mundo rural pampeano) consiente a Eduarda marcar a los europeos que ellos también fueron y siguen siendo bárbaros: "se combate entre nosotros, es verdad; en Europa se combate también, y aquí como allá, se ven siempre enfrentadas las grandes corrientes que agitan los mundos" (Mansilla, 2007, p. 33).

Y una cuestión por ser destacada es que, en la escritura, Mansilla se ocupa puntualmente de dejar ciertas advertencias a sus lectores europeos, respecto de los inmigrantes que llegan a la Argentina provenientes de Europa, puesto que estos escapan de males que aquejan a sus tierras. En un tono admonitorio, como de reproche, leemos: "para ellos, seremos siempre unos salvajes. Es hora de que aprendan a juzgarnos de otro modo" (Mansilla, 2007, p. 192).

Entonces, vemos que en la obra de Eduarda la barbarie es concebida como violencia de la condición humana, de las que nadie está exento. La barbarie social en que la sociedad hace vivir a las mujeres no se soluciona con la importación de modelos, sino con la comprensión profunda de lo que sucede en el tejido interno de la comunidad, en la percepción de las necesidades locales y en la administración de justicia y reconocimiento de los derechos de los subalternos.

La construcción de la topología de la barbarie que propone Eduarda (y que también hará su hermano) se evidencia con claridad en la novela que estamos analizando. 
En la intemperie salvaje y despojada los dos Mansilla, encuentran, empero, encantos secretos, atmósferas mágicas que incitan la imaginación y diluyen las fronteras entre lo real y lo soñado. (...) La dicotomía unitarios/federales, que vinculaba los unos a la "civilización" y los otros a la "barbarie" no es menos cuestionada. No se trata simplemente de invertir la valoración de los términos, sino de mostrar que unos no son mejores que los otros cuando ejercen el poder o practican la guerra, y que ningún bando representa, de por sí, la ilustración o el bienestar. (Lojo, 2005, p. 21)

La novela de Eduarda emprende un diálogo con el sistema pseudocientífico de Sarmiento, poniéndolo en discusión y construyendo un sólido posicionamiento en relación con el sistema político-identitario sarmientino. Desde esta perspectiva, podemos apreciar en Pablo una suerte de lectura en clave del Facundo, en la que la escritora nos ofrece su propia interpretación de la realidad argentina a partir del análisis personal que efectúa tanto de la sociedad como de la cultura argentinas.

No será la última vez que Eduarda escoja como interlocutor a Sarmiento. Años después volverá a hacerlo cuando escriba y publique en 1892 Recuerdos de viaje.

De esta manera, en la obra Pablo o la vida en las pampas (1869) dialoga con la obra de Sarmiento y revisa los diversos tópicos que el autor propone.

María Rosa Lojo lo plantea en estos términos: "representará a su país de otra manera: mostrándose a los extranjeros como 'modelo de argentina', y escribiendo políticamente (en Pablo ou la vie dans les pampas) sobre la justa apreciación de la 'barbarie' en Hispanoamérica” (Lojo, 2004, p. 4).

En correlación con esta línea Graciela Batticuore (2005, p. 226) sostiene que el rasgo característico de este ser escritora de Eduarda se nutre por su capacidad de mostrar América a los europeos, honrando y exaltando la literatura nacional.

Carlos Gamerro (2015) acierta cuando sostiene que la obra de Sarmiento, desde su título, se construye sobre un sistema de disyunciones. La dicotomía esencial de civilización y barbarie se acopla a otras tantas que van delineando el sendero de un discurso agónico continuo, inevitable. Unitarios o federales, Europa o América, Buenos Aires o el interior, progreso o tradición, ciudad o campo. De uno y otro lado se construye la historia de nuestro ser argentinos, diametralmente desbordada de opuestos.

En estos puntos encontramos la clave del diálogo que propone, literariamente, Mansilla en su novela. Los pares dicotómicos tan claros, precisos y definidos por Sarmiento, en Pablo se vuelven borrosos, confusos.

El discurso del sanjuanino no observa solución más allá del triunfo de alguna de las dos partes. En la obra Facundo esto cobra valor, puesto que la alternativa posible es el triunfo de la civilización por sobre la barbarie, a través la eliminación del caudillo, de la sustitución del gaucho por el inmigrante, del exterminio físico del salvaje. 
porque en Facundo Quiroga no veo un caudillo simplemente, sino una manifestación de la vida argentina, tal como lo han hecho la colonización y las peculiaridades del terreno, a lo cual creo necesario consagrar una seria atención, porque sin esto, la vida y hechos de Facundo Quiroga son vulgaridades que no merecían entrar, sino episódicamente, en el dominio de la historia. Pero Facundo, en relación con la fisonomía de la naturaleza grandiosamente salvaje que prevalece en la inmensa extensión de la República Argentina; Facundo, expresión fiel de una manera de ser de un pueblo, de sus preocupaciones e instintos. (Sarmiento, 2004, p. 17)

Por el contrario, y tal como pudimos apreciar, Mansilla considera que la solución o el triunfo estaría en la disolución del pensamiento dicotómico, verdadero mal que corroe las venas de la argentinidad decimonónica.

\section{Breves conclusiones}

La literatura del siglo XIX escrita por mujeres ha sido descalificada por muchos críticos del siglo XX, por considerarla intrascendente o superficial; por asumir que, al no recibir una educación equivalente a la de los hombres, esas mujeres no tenían la capacidad analítica apropiada para tratar los temas trascendentales para la formación de la argentina. Sin embargo, para poder comprender la identidad nacional, es necesario conocer y re-conocer las obras de las mujeres que quedaron invisibilizadas por la escritura masculina.

Marina Guidotti

Eduarda Mansilla se instala como escritora en un mundo de hombres (en un género que pareciera ser privativo de los varones), y allí adquiere su reconocimiento, su respeto. Junto con Lucio $\mathrm{V}$. Mansilla se cuestiona las bases de la dicotomía fundante de nuestra historia, la de civilizaciónbarbarie, puesto que la considera, tal como lo enuncia Lojo (2005, p. 38), simplificadora y peligrosa.

En Pablo o la vida en las pampas exhibe una suerte de alegato a favor del gaucho, iniciando el camino que luego retomarán su hermano en 1870 y Hernández en 1872.

Como escritora e intérprete cultural, Eduarda ratifica la conquista de una identidad que hizo frente a la domesticación femenina de la época, no sin por ello pagar el precio de cierta condena social.

Mediación, traducción, contacto permanente con el extranjero, cosmopolitismo, refinamiento, son términos y situaciones que sellaron el destino de Eduarda, sin por ello abandonar su profunda identidad criolla, asociada con el pasado federal de su familia, con el mundo rural y con el legado de la antigua tradición hispánica. Todos estos aspectos desembocan en su obra y en los debates que la atraviesan. Su función como intérprete cultural no es reproductiva, sino productiva. No presenta copia de originales ya existentes, sino que ofrece originales.

Desde la tensión intercultural, Eduarda Mansilla pudo sentar las bases de su posicionamiento como mujer e intelectual (como mujer escritora). Asimismo, a través de diversas 
vías supo consolidarse de forma original, sobre los cimientos de su propia identidad de género y su pertenencia latinoamericana.

Así como Carlos Gamerro (2015) sostiene que lo que hace la obra de Sarmiento es mantenernos hundidos en la barbarie, puesto que es salvaje pero grandioso, bárbaro pero romántico; es, igualmente, lo que nos representa. De esta manera, se pone de manifiesto el conflicto respecto de los modos de identidad, a la que podríamos enunciar como la identidad de origen y la aspiracional. Por el contrario, Mansilla nos desprende del estigma condenatorio de la barbarie como componente de exclusión.

Las dicotomías que se establecieron y consolidaron enérgicamente en la obra del sanjuanino, ahora son revisadas, repensadas y desarticuladas por esta escritora y la representación que hace del mundo rural de la argentina decimonónica.

\section{Referencias bibliográficas}

Batticuore, G. (2005). La mujer romántica: lectoras, autoras y escritores en la Argentina: 1830-1870. Buenos Aires, Edhasa.

Drucaroff, E. (dir. del tomo) y Jitrik, N. (dir. de colección) (2010). Historia crítica de la literatura argentina. La narración gana la partida (Tomo 11). Buenos Aires, Emecé.

Gamerro, C. (2015). Facundo o Martín Fierro. Los libros que inventaron la Argentina. Buenos Aires, Sudamericana.

Guidotti, M. (2015). Eduarda Mansilla en la prensa (1860-1892) y la escritura del yo. En Mansilla de García, E. (ed. y comp.), Escritos periodísticos completos (860-1892) (pp. 11-230). Buenos Aires, Corregidor.

Lojo, M. R. (1999). El imaginario de las Pampas en francés: de Eduarda Mansilla a Guillemette Marrier. La función narrativa y sus nuevas dimensiones (pp. 339-347). Centro de Estudios de Narratología, Universidad de Buenos Aires.

Lojo, M. R. (2004). Algunas relecturas del Facundo a fines del siglo XIX. Silabario. Revista de Estudios y Ensayos Neoculturales. VII (7), 33-46.

Lojo, M. R. (2005). Los hermanos Mansilla: más allá del pensamiento dicotómico, o cómo se escribe una Argentina completa. En Page, C. (coord.), En tiempos de Eduarda y Lucio V. Mansilla (pp. 15-41). Córdoba, Junta Provincial de Historia de Córdoba.

Lojo, M. R. (2007). Eduarda Mansilla, la traducción rebelde. Feminaria, XVI (30/31), 97-99.

Mansilla, E. (2007). Pablo o la vida en las pampas. Buenos Aires, Colihue / Biblioteca Nacional. (Original de 1869.) 
Mizraje, G. (2007). Eduarda Mansilla o la pampa ilustrada. Eduarda Mansilla, presente (o las idas y vueltas de la vida en las pampas). En Mansilla, E. (2007), Pablo o la vida en las pampas. Colihue, Biblioteca Nacional.

Sarmiento, D. F. (2004). Facundo o civilización y barbarie en las pampas argentinas. Buenos Aires, Agebe. (Original de 1845.)

* Milagros Rojo Güiñazú es Profesora y Licenciada en Letras (UNNE), Especialista en Docencia Universitaria (UNNE) y Especialista en Lectura, Escritura y Educación (FLACSO). Actualmente se encuentra en la etapa de redacción de su Tesis Doctoral (Doctorado en Letras, UCA). Es docente de la Facultad de Humanidades (UNNE, Letras) como Profesora Adjunta con dedicación semiexclusiva de la cátedra "Literatura Argentina I" (UNNE). Es investigadora Categoría III, codirige el PI 17H001 "El discurso feminista en la historia y en las narrativas de los siglos XIX a XXI" (SGCyT, UNNE). Es directora de Becaria CIN.

RECIBIDO: 20/09/2020

ACEPTADO: 27/01/2021 